\title{
Геохимия ультраосновных-щелочных пород и карбонатитов Большетагнинского массива (Восточный Саян)
}

\author{
Базарова Е.П., Савельева В.Б., Данилова Ю.В. \\ Институт земной коры СО РАН, Иркутск,bazarova@crust.irk.ru
}

\begin{abstract}
Аннотация. Приводятся новые данные о составе щелочных силикатных пород, карбонатитов и метасоматитов Большетагнинского массива. Выявлено, что среди алюмосиликатных пород преобладают породы калиевой серии, но среди них встречаются породы натриевой серии. По сравнению с фельшпатоидными породами, субщелочные полевошпатовые сиениты обеднены редкоземельными элементами, имеют более фракционированное распределение легких РЗЭ и отрицательную Еu-аномалию, а по сравнению с ийолит-уртитами и нефелиновыми сиенитами - пониженные содержания Ti, Zr, Y, Sr, P, Pb, при повышенных содержаниях $\mathrm{Nb}$ и U. При сравнении редкоэлементных спектров кальцитовых карбонатитов со спектрами ийолитов и нефелиновых сиенитов отмечается обедненность карбонатитового расплава Zr, Hf, тяжелыми РЗЭ, Ү и обогащенность легкими РЗЭ относительно тяжелых, что можно рассматривать как признаки ликвационного происхождения карбонатного расплава.
\end{abstract}

Ключевые слова: Большетагнинский массив, карбонатиты, ультраосновные породы, геохимия.

\section{Geochemistry of ultramafic-alkaline rocks and carbonatites of the Bol'shetagninsky massif (Eastern Sayan)}

\author{
Bazarova E.P., Savelyeva V.B., Danilova Yu.V. \\ Institute of the Earth's Crust SB RAS, Irkutsk, bazarova@crust.irk.ru
}

\begin{abstract}
New data of the composition of alkaline silicate rocks, carbonatites and metasomatites of the Bol'shetagninsky massif are presented in this paper. It was revealed that rocks of the potassium series predominate among aluminosilicate rocks, but among it there are rocks of the sodium series. Compared with felspathoid rocks, subalkaline feldspar syenites are depleted in the REE, also it have a more fractionated distribution of light REE and a negative Eu-anomaly. Compared with ijolite-urtites and nepheline syenites, subalkaline feldspar syenites have lower contents of $\mathrm{Ti}, \mathrm{Zr}, \mathrm{Y}, \mathrm{Sr}, \mathrm{P}, \mathrm{Pb}$ and a high contents of $\mathrm{Nb}$ and $\mathrm{U}$. When comparing the rare-element spectra of calcite carbonatites with spectra of ijolites and nepheline syenites, the depletion of the carbonatite melt in $\mathrm{Zr}$, Hf, heavy REE, $\mathrm{Y}$ and enrichment in light REE are noted. This feature can be considered as signs of the liquation origin of the carbonate melt.
\end{abstract}

Key words: Bol'shetagninsky massif, carbonatites, ultramafic rocks, geochemistry.

Специфической особенностью состава карбонатитов является их обогащенность редкими элементами, которые широко применяются в различных отраслях промышленности. С карбонатитами связаны крупнейшие месторождения $\mathrm{Nb}, \mathrm{Ta}, \mathrm{P} 3 Э, \mathrm{Zr}, \mathrm{Ba}, \mathrm{Sr}, \mathrm{Th}, \mathrm{Fe}$, а также апатита, флогопита и флюорита. Щелочно-карбонатитовые комплексы характеризуются многообразной и сложной минерализацией, при этом пока не выяснены до конца механизмы распределения рудных компонентов и образования месторождений редкоземельных элементов и ниобия. Сложной проблемой является также генезис карбонатитов. На образование данных пород существует три взгляда: (1) фракционная кристаллизация карбонатизированной силикатной магмы, (2) жидкостная карбонатносиликатная несмесимость, (3) выплавление из карбонатизированных мантийных перидотитов.

Большетагнинский массив, входящий в зиминский комплекс ультраосновных пород и карбонатитов вендского возраста, отличается от других массивов комплекса широким распространением субщелочных микроклиновых сиенитов, внедрение которых вызвало интенсивный метасоматоз более ранних щелочных пород. Массив находится в юго-западной части Сибирской платформы в зоне ее сочленения с Алтае-Саянской складчатой областью. Вмещающие породы представлены песчаниками и серицит-хлоритовыми сланцами и песчаниками игнашинской свиты нижнего рифея и углисто-глинистыми сланцами и песчаниками урикской свиты нижнего протерозоя. Большетаг- 
нинский массив имеет округлую форму при зонально-кольцевом строении и сложен пироксеннефелиновыми породами серии мельтейгит - ийолит-уртит, нефелиновыми и щелочными сиенитами, калишпатовыми сиенитами и карбонатитами, также отмечаются дайки пикритовых порфиритов - альнеитов (Кожевников и др., 1974; Фролов, Багдасаров, 1967; Фролов, Белов, 1999).

В работе приводятся новые данные о составе щелочных силикатных пород массива, карбонатитов и метасоматитов с целью выявления особенностей распределения химических элементов, в том числе рудных компонентов.

Химический состав пород изучен в Институте земной коры СО РАН г. Иркутска методом силикатного анализа (аналитик Самойленко М.M.), методом ICP-MS (аналитик Пантеева С.В.) в ОПЦКП «Ультрамикроанализ» на квадрупольном масс-спектрометре Agilent 7500 ce (Agilent Technologies Inc., США) по методике (Panteeva et al., 2003) и методом рентгенофлюоресцентного анализа (аналитик Худоногова Е.В.).

Щелочные силикатные породы представлены ийолитами, уртитами и сиенитами (нефелиновые, эгириновые, калишпатовые).

Ийолиты сложены диопсидом, эгирин-диопсидом и нефелином, присутствуют меланит и апатит, единичные зерна биотита. Породы часто калишпатизированы, карбонатизированы и биотитизированы и характеризуются минимальными по сравнению с другими силикатными породами массива коэффициентом агпаитности (Кагп) (0.58) и суммой щелочей $\mathrm{Na}_{2} \mathrm{O}$ и $\mathrm{K}_{2} \mathrm{O}(5.9)$ при сильно варьирующем и в целом низком отношении $\mathrm{Na}_{2} \mathrm{O} / \mathrm{K}_{2} \mathrm{O}(0.03-0.83)$ за счет наложенной микроклинизации, но при этом наибольшими содержаниями $\mathrm{CaO}$ (20.1 мас. \%), Со (15.7) и W (5.1) (ppm).

Образец уртита сложен преимущественно канкринитизированным нефелином, присутствуют также биотит, гранат и апатит. При наименьшем по сравнению с другими силикатными породами комплекса содержании кремнезема $\mathrm{SiO}_{2}(32.8)$, уртит отличается наиболее высоким отношением $\mathrm{Na}_{2} \mathrm{O} / \mathrm{K}_{2} \mathrm{O}$ (4.1) и наибольшими содержаниями $\mathrm{TiO}_{2}(2.4), \mathrm{Al}_{2} \mathrm{O}_{3}$ (15.7), $\mathrm{MgO}$ (3.4), $\mathrm{Na}_{2} \mathrm{O}$ (7.5) (мас. \%), F (0.6) и Та (6.1) (ppm).

Нефелиновые сиениты сложены нефелином, калиевым полевым шпатом, нередко замещающим нефелин, пироксеном - диопсидом и титан-авгитом, также присутствуют биотит, кальцит, апатит, рудные минералы и гранат, при этом иногда отмечается порфировидная структура (порфировые выделения нефелина и калиевого полевого шпата). Среднее содержание $\mathrm{SiO}_{2}$ для данных пород 36.2 мас. \% при сумме $\mathrm{Na}_{2} \mathrm{O}$ и $\mathrm{K}_{2} \mathrm{O} 7.4$ мас. \% и Кагп 0.6. При повышении $\mathrm{SiO}_{2}$ происходит снижение Кагп (рис. 1 a). Отношение $\mathrm{Na}_{2} \mathrm{O} / \mathrm{K}_{2} \mathrm{O}$ низкое (0.02-0.17), что обусловлено наложенной микроклинизацией. По сравнению с другими силикатными породами массива нефелиновые сиениты характеризуются наибольшими содержаниями $\mathrm{MnO}$ (0.53), $\mathrm{P}_{2} \mathrm{O}_{5}$ (1.3) (мас. \%), Zn (213), Ge (1.3), $\mathrm{Zr}(526)$, Mo (3.5), Ba (3161), Y (53), $\mathrm{Hf}$ (7.2), Tl (0.5), Pb (14.4) и Th (3.9) (ppm).

Образец эгиринового сиенита сложен калиевым полевым шпатом и эгирином, в подчиненном количестве отмечаются также кальцит, доломит, апатит, стронцианит, пирохлор. Эгириновый сиенит характеризуется наиболее высоким для исследуемых силикатных пород массива содержанием $\mathrm{SiO}_{2}(52.4$ мас. \%), суммой щелочей (12.5 мас. \%) и Кагп (1.7), а также наибольшими содержаниями $\mathrm{Fe}_{2} \mathrm{O}_{3}(9.4$ мас. \%), V (1009), $\mathrm{Cr}$ (45), Ni (22), Ga (62), Sr (1779) и $\mathrm{Sn}$ (2.1) (ppm).

Калишпатовые сиениты (микроклиниты) практически нацело сложены калиевым полевым шпатом с незначительной примесью апатита, биотита, гематита и рудных минералов (рутил, пирит, сфалерит). Содержание $\mathrm{SiO}_{2} 47.3$ мас. \% при сумме щелочей 10.7; отношение $\mathrm{Na}_{2} \mathrm{O} / \mathrm{K}_{2} \mathrm{O}$ варьирует от 0.52 в альбитизированных сиенитах до 0.01 , содержания СаО изменяются в широких пределах от 0.7 до 10.6. Коэффициент агпаитности 0.96, при этом в отличие от нефелиновых сиенитов при повышении кремнекислотности Кагп повышается. По сравнению с другими силикатными породами массива, калишпатовые сиениты характеризуются наибольшими содержаниями $\mathrm{K}_{2} \mathrm{O}$ (8.8 мас. \%), $\mathrm{Cu}$ (25), Rb (215), Nb (392), Cs (1.9) и U (3.4) (ppm).

Для всех изученных разностей силикатных щелочных пород с увеличением $\mathrm{SiO}_{2}$ растет сумма щелочей (рис. 1 б). 
a

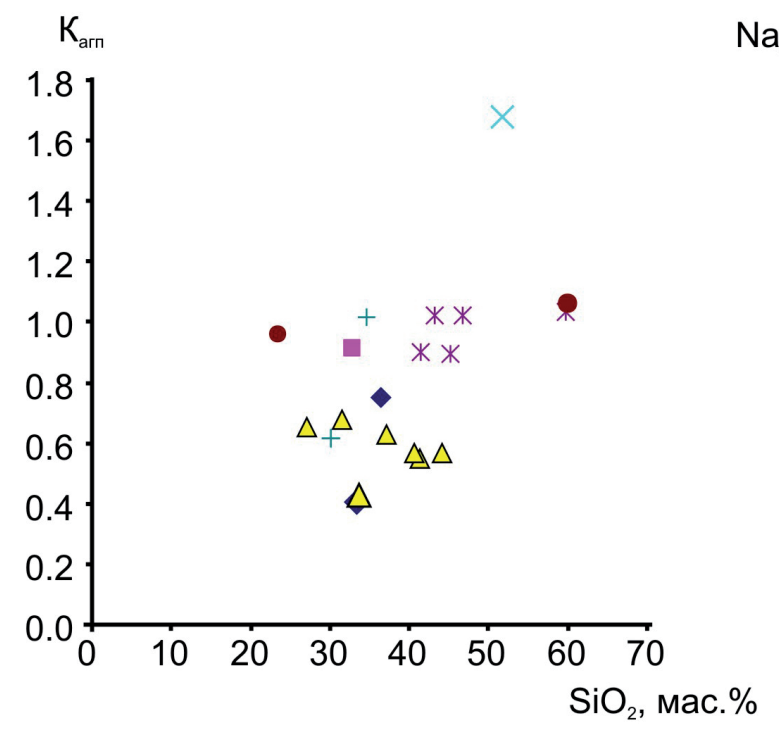

б

$\mathrm{Na}_{2} \mathrm{O}+\mathrm{K}_{2} \mathrm{O}$

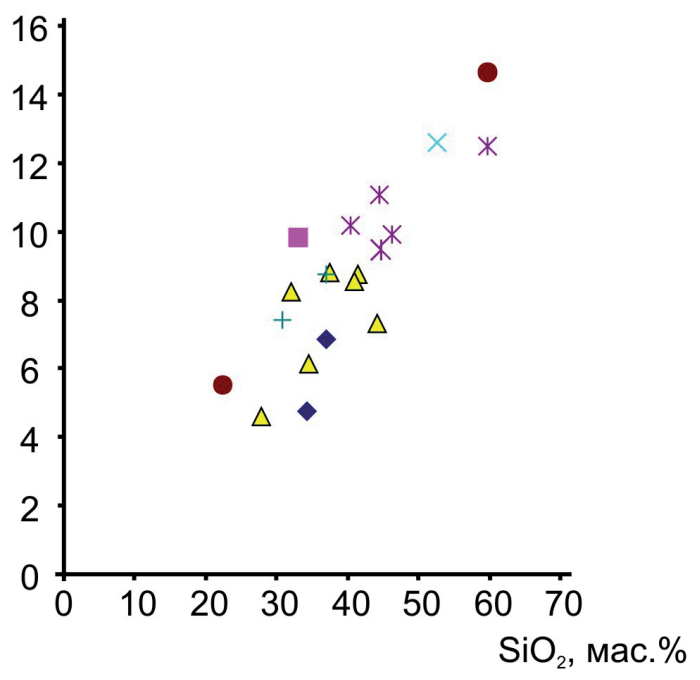

B

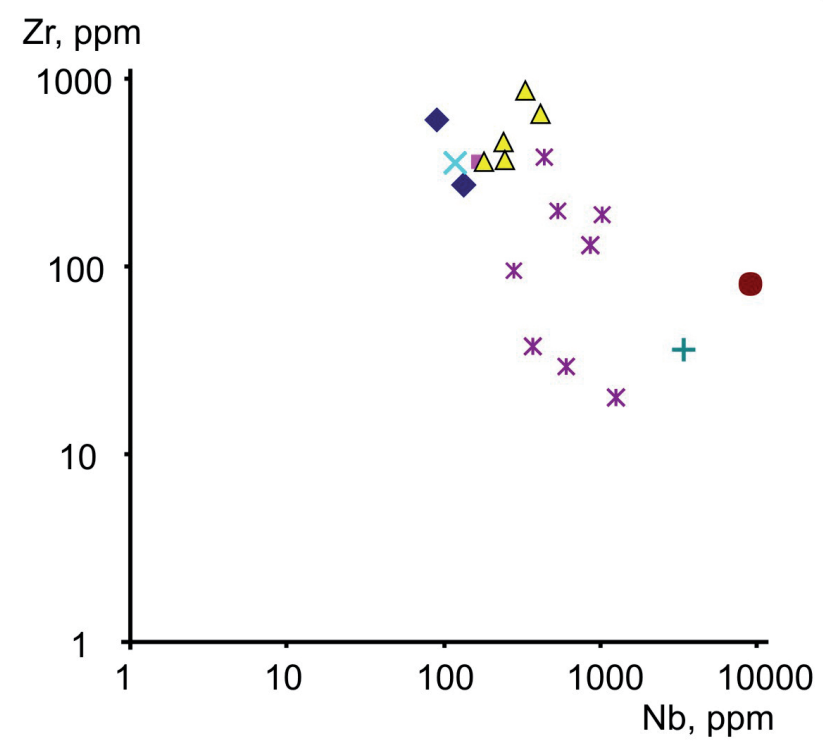

Y, ppm

r

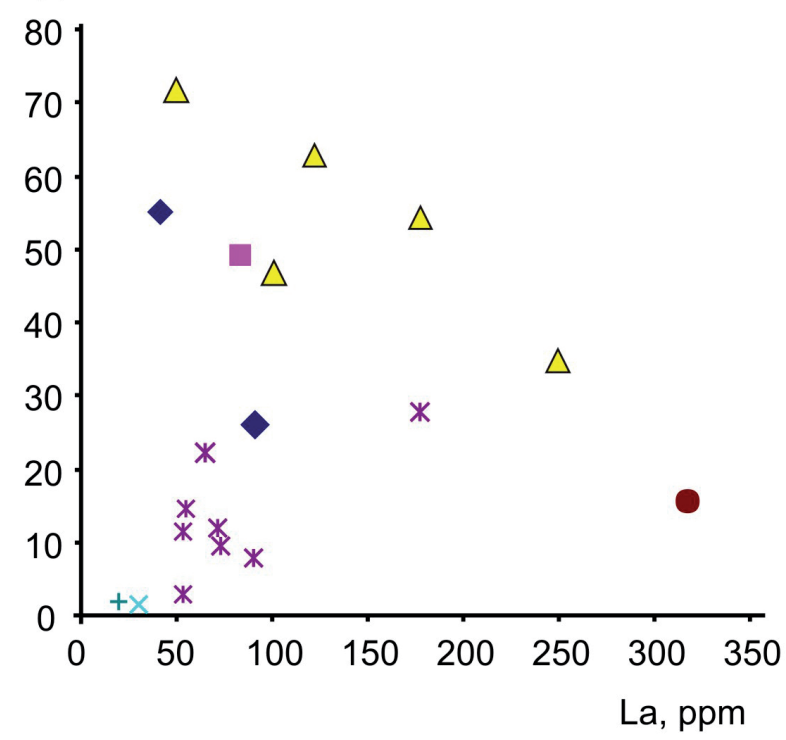

- ийолиты

- уртит

$\triangle$ нефелиновые сиениты

× эгириновые сиениты

* микроклиниты

- микроклин-апатитовые метасоматиты

+ слюдистые метасоматиты

Рис. 1. Бинарные диаграммы: а - соотношения $\mathrm{SiO}_{2}$ и коэффициента агпаитности, б - соотношения $\mathrm{SiO}_{2}$ и суммы щелочей; в - соотношения $\mathrm{Nb}$ и $\mathrm{Zr}$, г - соотношения La и Y для силикатных щелочных пород Большетагнинского массива.

Fig. 1. Binary diagrams: a - the ratio of $\mathrm{SiO}_{2}$ and coefficient of agpaite, $\mathrm{b}$ - the ratio of $\mathrm{SiO}_{2}$ and the sum of alkalis, $\mathrm{c}$ - the ratio of $\mathrm{Nb}$ and $\mathrm{Zr}, \mathrm{d}$ - the ratio of $\mathrm{La}$ and $\mathrm{Y}$ for silicate alkaline rocks of the Bol shetagninsky massif.

Что касается редких и редкоземельных элементов, то наибольшее суммарное содержание РЗЭ отмечается для нефелиновых сиенитов (418 ppm), наименьшее - для образца эгириновых сиенитов (81 ppm). Спектры Р3Э для всех изученных образцов имеют отрицательный наклон, что указывает на обеднение тяжелыми РЗЭ (рис. 2 б). Во всех изученных разновидностях силикатных щелочных пород легкие лантаноиды преобладают над тяжелыми $\left(\mathrm{La}_{\mathrm{N}} / \mathrm{Yb}_{\mathrm{N}}\right.$ от 20.2 для уртита до 28.6 для эгири- 

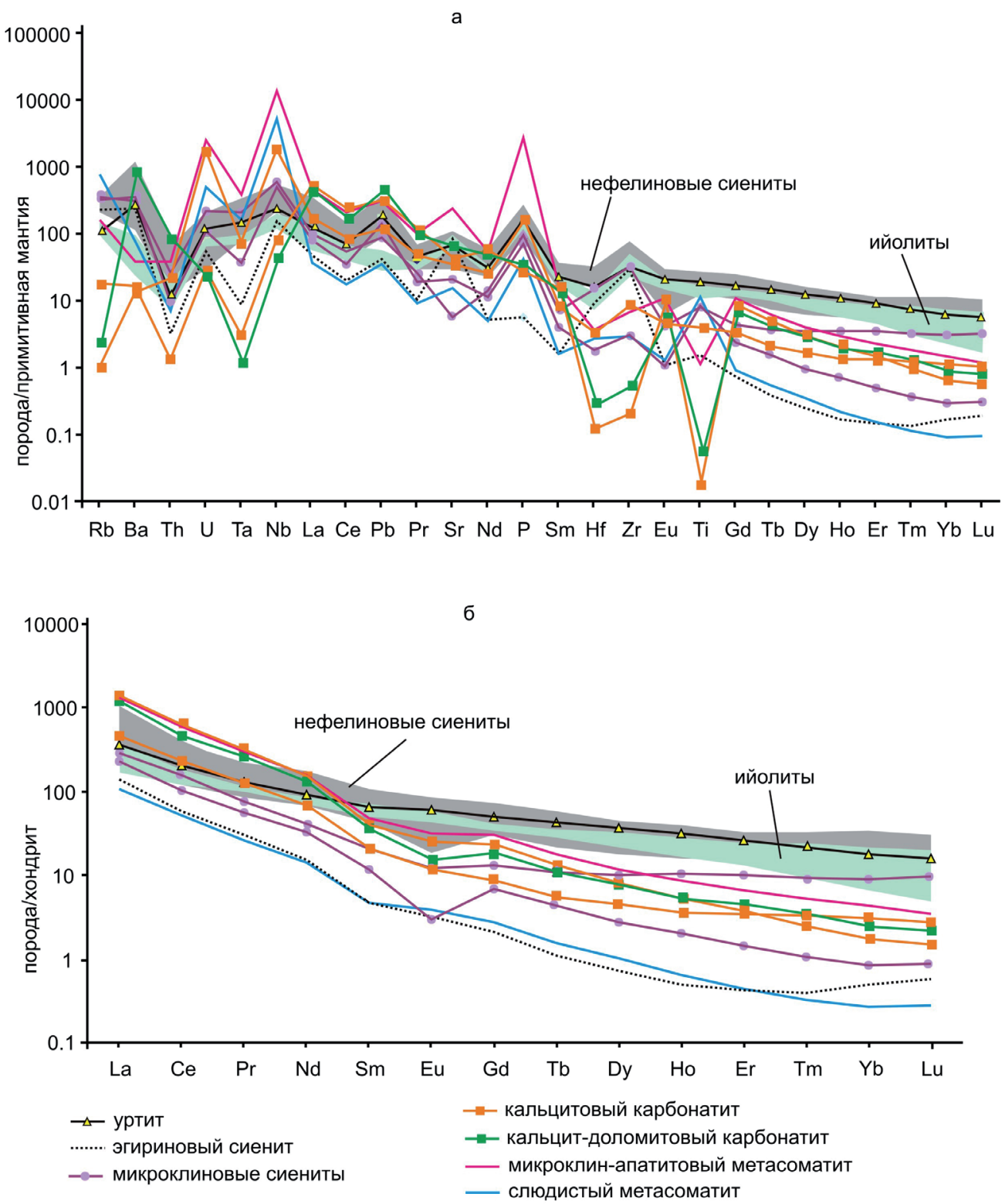

Рис. 2. Содержание редких (а) и редкоземельных (а) элементов в породах Большетагнинского массива, нормированных к примитивной мантии и хондриту по (Sun, McDonough, 1989).

Fig. 2. Content of rare (a) and rare earth (b) elements in the rocks of the Bol 'shetagninsky massif, normalized to primitive mantle and chondrite after (Sun, McDonough, 1989).

нового сиенита при $\mathrm{Gd}_{\mathrm{N}} / \mathrm{Yb}_{\mathrm{N}}$ от 1.98 для нефелиновых сиенитов до 4.8 для калишпатовых сиенитов). Незначительная европиевая аномалия отмечается только для спектров калишпатовых сиенитов, что может указывать на то, что при образовании породы в результате фракционной кристаллизации или частичного плавления плагиоклаз остается в источнике. На графиках содержаний редких элементов, нормированных к примитивной мантии, для всех разностей силикатных пород отмечаются отрицательные аномалии $\mathrm{Th}$, для большинства пород $\mathrm{Ce}, \mathrm{Pr}, \mathrm{Nd}, \mathrm{Sm}$, а для эгиринового сиенита - Ta; и положительные аномалии $\mathrm{Nb}, \mathrm{P}, \mathrm{Pb}$ и $\mathrm{Zr}$ для большинства пород, а также Ва для нефелиновых сиенитов, U для эгиринового сиенита и Ті для калишпатовых сиенитов (рис. 2 a).

Карбонатиты представлены кальцитовой, кальцит-доломитовой и доломитовой разновидностями, сложенными кальцитом и доломитом, в составе кальцитовых карбонатитов отмечались также зерна эгирина и калиевого полевого шпата. Согласно классификационной диаграмме (Woolley, Kempe, 1989), кальцитовые карбонатиты относятся к кальциокарбонатитам, доломитовые карбонати- 
ты по своему составу варьируют от магнезиокарбонатитов до феррокарбонатитов. По сравнению с силикатными щелочными породами в карбонатитах повышены содержания Zn (338-495) и W (8.7-44). Суммарное содержание РЗЭ в кальцитовых карбонатитах выше, чем в силикатных щелочных породах $(560 \mathrm{ppm})$, легкие лантаноиды преобладают над тяжелыми $\left(\mathrm{La}_{\mathrm{N}} / \mathrm{Yb}_{\mathrm{N}}=467.5, \mathrm{Gd}_{\mathrm{N}} / \mathrm{Yb}_{\mathrm{N}}=8.2\right)$ (рис. 2 б). Sr преобладает над Ва, отношение $\mathrm{Sr} / \mathrm{Ba} 7.8$.

Микроклин-апатитовые метасоматиты сложены калиевым полевым шпатом и апатитом и содержат максимальное количество пирохлора. Содержание $\mathrm{SiO}_{2} 40.9$ при сумме щелочей $\mathrm{Na}_{2} \mathrm{O}$ и $\mathrm{K}_{2} \mathrm{O}$ 9.9, отношение $\mathrm{Na}_{2} \mathrm{O} / \mathrm{K}_{2} \mathrm{O}$ 0.02. По сравнению с вышеописанными силикатными щелочными породами микроклин-апатитовые метасоматиты характеризуются повышенными содержаниями $\mathrm{K}_{2} \mathrm{O}$ (9.8), $\mathrm{P}_{2} \mathrm{O}_{5}$ (12.7) (мас. \%), $\mathrm{Sr}$ (5053), $\mathrm{Nb}$ (9616), $\mathrm{La}$ (316), $\mathrm{Ce}$ (364), $\operatorname{Pr}(28), \mathrm{Nd}(74), \mathrm{P}(261300), \mathrm{Ta}(16)$, $\mathrm{U}(51)$ (ppm). Слюдистые метасоматиты (слюдиты) сложены биотитом, кальцитом, метасоматически замещающим ийолиты и сиениты, отмечаются апатит, магнетит, пирохлор и ильменит. По сравнению с силикатными щелочными породами, слюдиты отличаются повышенными концентрациями $\mathrm{FeO}$ (10.2), MgO (5.9) (мас. \%), Zn (920), Ga (79), Ge (1.4), Rb (494), Cs (4.8) (рpm). Суммарное содержание РЗЭ составляет 804 pрm для микроклин-апатитовых метасоматитов и только 67 для слюдитов (наименьшее среди исследованных разностей пород). В обеих разновидностях метасоматитов легкие лантаноиды преобладают над тяжелыми $\left(\mathrm{La}_{\mathrm{N}} / \mathrm{Yb}_{\mathrm{N}}=305.7, \mathrm{Gd}_{\mathrm{N}} / \mathrm{Yb}_{\mathrm{N}}=7.1\right.$ для микроклинапатитовых, $\mathrm{La}_{\mathrm{N}} / \mathrm{Yb}_{\mathrm{N}}=397.7, \mathrm{Gd}_{\mathrm{N}} / \mathrm{Yb}_{\mathrm{N}}=10.2$. для слюдистых метасоматитов). Европиевая аномалия отсутствует для обеих разностей (рис. 2 б). На графиках содержания редких элементов, нормированных к примитивной мантии, для микроклин-апатитовых метасоматитов отмечаются отрицательные аномалии Th, Ta, $\mathrm{Nd}$, Ti и положительные - U, Nb, P; для слюдитов наблюдаются те же аномалии, за исключением положительной аномалии Ті (рис. 2 a).

Полученные данные показывают, что алюмосиликатные породы массива неоднородны по химическому составу. Преобладают породы калиевой серии $\left(\mathrm{Na}_{2} \mathrm{O} / \mathrm{K}_{2} \mathrm{O}<1\right)$, куда относятся и микроклинизированные и ийолиты, но среди них встречаются породы натриевой серии (уртит). При общем сходстве спектров распределения редких элементов в щелочных и субщелочных породах (минимум по Th, максимум по $\mathrm{Nb}, \mathrm{Pb}, \mathrm{P}, \mathrm{Sr}, \mathrm{Zr}$ ), субщелочные полевошпатовые сиениты по сравнению с фельдшпатоидными породами характеризуются общей обедненностью редкоземельными элементами и особенно тяжелыми лантаноидами, более фракционированным распределением легких РЗЭ $\left(\mathrm{La}_{\mathrm{N}} / \mathrm{Sm}_{\mathrm{N}}=14-28\right.$ в полевошпатовых сиенитах и преимущественно 3-8 в ийолитах, уртите и нефелиновых сиенитах), наличием отрицательной Еu-аномалии $\left(\mathrm{Eu} / \mathrm{Eu}^{*}=0.33-0.75\right)$. Кроме того, по сравнению с ийолит-уртитами и нефелиновыми сиенитами в них в целом ниже содержания $\mathrm{Ti}, \mathrm{Zr}, \mathrm{Y}, \mathrm{Sr}, \mathrm{P}$, $\mathrm{Pb}$, но выше $\mathrm{Nb}, \mathrm{U}$ (рис. 1 и 2).

Отсутствие корреляции между высокозарядными элементами в щелочных и субщелочных породах (рис. 1 в, г) не позволяет связывать формирование этих пород с фракционной кристаллизацией щелочного калиево-натриевого расплава. В то же время, геохимические особенности субщелочных сиенитов указывают на вероятное присутствие титанового граната в источнике или его фракционирование.

Сравнение редкоэлементных спектров кальцитовых карбонатитов с спектрами ийолитов и нефелиновых сиенитов показывает резкую обедненность карбонатитового расплава Zr, Hf, тяжелыми Р3Э, Y (рис. 1 г) и резкую обогащенность легкими Р3Э относительно тяжелых $\left(\mathrm{La}_{\mathrm{N}} / \mathrm{Yb}_{\mathrm{N}}=150-803\right)$, что можно рассматривать как признаки ликвационного происхождения карбонатного расплава (Veksler et al., 2012).

Работа выполнена при финансовой поддержке Интеграционного проекта ИНЦ СО РАН, блок 1.4.

\section{Литература}

1. Кожевников О.К., Кухринкова Н.В., Туголукова Г.А. Больше-Тагнинский массив ультраосновных щелочных пород и карбонатитов / Эндогенные полезные ископаемые Саяно-Байкальской горной области. Иркутск. Изд-во: Восточно-Сибирское книжное изд-во. 1974. С. 134-163. 
2. Фролов А.А., Багдасаров Ю.А. Большетагнинский массив ультраосновных щелочных пород и карбонатитов // Советская геология. 1967. № 12. С. 80-93.

3. Фролов А.А., Белов С.В. Комплексные карбонатитовые месторождения Зиминского рудного района (Восточный Саян, Россия) // Геология рудных месторождений. 1999. Т. 41. № 2. С. 109-130.

4. Panteeva S.V., Gladkochoub D.P., Donskaya T.V., Markova V.V., Sandimirova G.P. Determination of 24 trace elements in felsic rocks by inductively coupled plasma mass spectrometry after lithium metaborate fusion // Spectrochimica Acta Part B: Atomic Spectroscopy. 2003. V. 58. 2. P. 341-350.

5. Sun S.-S., McDonough W.F. Chemical and isotopic systematics of oceanic basalts: implications for mantle composition and processes // Geological Society, London, Special Publications 1989. V. 42. P. 313-345.

6. Veksler I.V., Dorfman A.M., Dulski P., Kamenetsky V.S., Danyushevsky L.V., Jeffries T., Dingwell D.B. Partitioning of elements between silicate melt and immiscible fluoride, chloride, carbonate, phosphate and sulfate melts, with implications to the origin of natrocarbonatite // Geochimica Cosmochimica Acta. 2012. V. 79. P. 20-40.

7. Woolley A.R., Kempe D.R.C. Carbonatites: nomenclature, average chemical composition and element distribution // Carbonatites: genesis and evolution. London, 1989. P. 1-46. 